\title{
Morphological characteristics of urban water bodies: mechanisms of change and implications for ecosystem function
}

\author{
M. K. Steele ${ }^{1}$ and J. B. Heffernan \\ Nicholas School of the Environment, Duke University, Durham, North Carolina 27708 USA
}

\begin{abstract}
The size, shape, and connectivity of water bodies (lakes, ponds, and wetlands) can have important effects on ecological communities and ecosystem processes, but how these characteristics are influenced by land use and land cover change over broad spatial scales is not known. Intensive alteration of water bodies during urban development, including construction, burial, drainage, and reshaping, may select for certain morphometric characteristics and influence the types of water bodies present in cities. We used a database of over one million water bodies in 100 cities across the conterminous United States to compare the size distributions, connectivity (as intersection with surface flow lines), and shape (as measured by shoreline development factor) of water bodies in different land cover classes. Water bodies in all urban land covers were dominated by lakes and ponds, while reservoirs and wetlands comprised only a small fraction of the sample. In urban land covers, as compared to surrounding undeveloped land, water body size distributions converged on moderate sizes, shapes toward less tortuous shorelines, and the number and area of water bodies that intersected surface flow lines (i.e., streams and rivers) decreased. Potential mechanisms responsible for changing the characteristics of urban water bodies include: preferential removal, physical reshaping or addition of water bodies, and selection of locations for development. The relative contributions of each mechanism likely change as cities grow. The larger size and reduced surface connectivity of urban water bodies may affect the role of internal dynamics and sensitivity to catchment processes. More broadly, these results illustrate the complex nature of urban watersheds and highlight the need to develop a conceptual framework for urban water bodies.
\end{abstract}

Key words: connectivity of water bodies; hydrography; lakes; land cover; ponds; urban water bodies.

\section{INTRODUCTION}

Urban land cover has quadrupled over the last 50 years and covers $\sim 24$ million ha of land in the United States (Lubowski et al. 2006). Given the increase in urban land cover globally (Schneider et al. 2009, United Nations 2011), and the importance of water body morphology to aquatic ecosystems processes, understanding how the characteristics of water bodies in cities differ from those in undeveloped landscapes is an essential foundation for developing the ecological theory of urban aquatic systems, managing urban watersheds, and understanding the effects of urbanization on broader-scale processes.

The "urban stream syndrome" provides a general conceptual framework that integrates the numerous effects of watershed development and channel alteration on streams (Walsh et al. 2005). Urbanization alters flow regimes primarily by introducing impervious surface to the watershed, which leads to changes in channel morphology; activities taking place on those surfaces

Manuscript received 31 May 2013; revised 25 October 2013; accepted 29 October 2013. Corresponding Editor (ad hoc): J. C. Finlay.

${ }^{1}$ Present address: 328A Smyth Hall, 185 Ag Quad Lane (MC 0404), Virginia Tech, Blacksburg, Virginia 24061 USA. E-mail: meredith.steele@vt.edu also generate a suite of chemical and biotic repercussions including altered hydrologic and metabolic regimes, nutrient enrichment, and reduced biodiversity (Paul and Meyer 2001, Meyer et al. 2005, Walsh et al. 2005, Steele et al. 2010). While most efforts have focused on the effects of urbanization at the scale of individual stream reaches (see Meyer and Wallace 2001), some recent studies have more explicitly addressed the landscapescale consequences of urbanization for watersheds and aquatic systems. For example, several recent studies have documented changes in stream channel density in individual urban areas (Elmore and Kaushal 2008, Roy et al. 2009) and across large numbers of cities (Steele et al. 2014). Other recent efforts have incorporated engineered infrastructure (such as storm water drainage ditches, pipe networks, buried streams) into our understanding of the flow paths of developed watersheds (Kaushal and Belt 2012, Somers et al. 2013). However, relatively few studies have addressed changes to other components of urban flow networks (e.g., lakes, ponds, wetlands, reservoirs; hereafter "water bodies"), which can mediate the movement of water, energy, and nutrients across watershed surfaces and between above- and belowground pools (Cole et al. 2007, Downing et al. 2008) and influence dispersal of both benthic and pelagic organisms throughout watersheds 
(Havel et al. 2002, Shurin et al. 2009). There is no analogous conceptual framework for urban water bodies (i.e., an "urban pond syndrome"). As such, the inattention to these aquatic systems in urban environments limits our ability to assess the hydrologic, biogeochemical, and ecological characteristics of urbanized watersheds at broad spatial scales.

As is true of urban streams, the limited number of studies on urban water bodies has primarily addressed change at the scale of individual ecosystems. For example, the loss and disturbance of urban wetlands and riparian zones have received significant attention as urban development alters hydrologic regimes and increases pollutants that impair the biogeochemical and ecosystem functions of wetlands (Groffman et al. 2002, Kentula et al. 2004, Stander and Ehrenfeld 2009, McKinney et al. 2011, Jiang et al. 2012, Sun et al. 2012). Research on urban lakes, ponds, and storm water detention ponds has addressed issues such as eutrophication, pollution, sedimentation, and shifts in biotic communities (Birch and McCaskie 1999, Lindstrom 2001, Leavitt et al. 2006, Novotny et al. 2008, Effler et al. 2010, Schagerl et al. 2010, Van Metre and Mahler 2010, Hamer and Parris 2011, Meter et al. 2011, Van Metre 2012). Changes may be mediated by morphological characteristics of water bodies (e.g., size, shape, and type), as well as broader, landscape-scale characteristics of lake districts and flow networks (e.g., water body density and connectivity (Oertli et al. 2002, Williams 2004, Céréghino et al. 2007, Downing 2010).

The hydrography of cities also provides an opportunity to explore the broad-scale mechanisms shaping urban development. Recently, we have shown that the abundance of surface water (as measured by area or numerical density of water bodies) in urban lands converges across large geographic regions (Steele et al. 2014). In many cities, surface water is less abundant (by number or area of features) than in the surrounding undeveloped land; however, cities located in drier landscapes tend to have abundances relatively greater than their surrounding undeveloped land (Steele et al. 2014). These patterns may reflect two broad types of processes: initial location of cities in regions with specific hydrographic characteristics, and alteration of surface water features during urban development by processes such as impoundment, excavation, drainage, and infilling. A limited number of case studies from large cities suggest that alteration has a major role in the development of urban hydrography (Elmore and Kaushal 2008, Roach et al. 2008, Roy et al. 2009, Larson and Grimm 2011), but whether these examples reflect a general dominance of alteration over site selection remains unclear.

The size and shape of water bodies has a broad range of effects on their hydrologic and geochemical conditions and their ecological and biogeochemical functions. Ponds, relative to larger water bodies, have been observed to have a higher number and richness of macroinverte- brate and plant species (Davies et al. 2007, De Bie et al. 2007). Other studies observed a low, positive impact of areal size on phytoplankton and fish (Søndergaard et al. 2005, Stomp et al. 2011). Other characteristics influenced by lake size include zooplankton community structure (Dodson et al. 2005, 2008) and bird diversity (Newbrey et al. 2005), and processes like fish parasite growth (Marcogliese and Cone 1991) and bird roosting site selection (Alvo et al. 1988). Ratios of shoreline to surface area, a fundamental descriptor of the shape of lakes, influence the number of fish species (Eadie and Keast 1984) and their patterns of movement (Woolnough et al. 2009), as well as the diversity of pisciverous birds (Newbrey et al. 2005). At the landscape scale, the density and distribution of water bodies influences the relative abundance of aquatically and aerially dispersed species (Dunham and Rieman 1999).

Small water bodies also differ from larger (and more intensively studied) lakes in terms of physical and biogeochemical conditions and processes (Downing 2010). For example, smaller lakes tend to be low in dissolved inorganic carbon and oxygen, but high in dissolved organic matter and dissolved $\mathrm{CO}_{2}$ (Crisman et al. 1998, Kelly et al. 2001, Hanson et al. 2007, Goodman et al. 2011). Consequently, lake size has been observed to impact methane production (Michmerhuizen et al. 1996, Bastviken et al. 2004) and $\mathrm{CO}_{2}$ efflux (Cole et al. 2007, Hanson et al. 2007). Areal rates of organic carbon sequestration are potentially an order of magnitude higher in small lakes (Dean and Gorham 1998, Stallard 1998, Downing et al. 2008, Downing 2010). Likewise, lake size also influences regional and global $\mathrm{N}$ budgets, as small lakes retain double the amount of nitrogen globally than large lakes and are sinks for $\mathrm{N}$ via denitrification (Harrison et al. 2008). The size distribution of water bodies is thus an important component in calculating regional to continental scale biogeochemical fluxes (Cole et al. 2007, Harrison et al. 2008).

Water body characteristics such as size, shape, and connectivity have implications for the inference of mechanisms that generate surface water patterns, for landscape scale ecological and biogeochemical processes, and for interactions between urban water bodies and their watersheds. The purpose of this study is to determine if and how these characteristics differ between urban landscapes and less-developed lands. To address this, we compared the morphological characteristics of over one million water bodies in urban and undeveloped land cover classes from 100 cities across the conterminous United States. Specifically, we evaluated the different types of water bodies, distribution of water body sizes, the tortuosity of the shorelines, and the connectivity of water bodies to streams and rivers.

\section{Materials And Methods \\ City selection and land cover}

We selected 100 cities with a defined metropolitan statistical area from the continental United States. The 


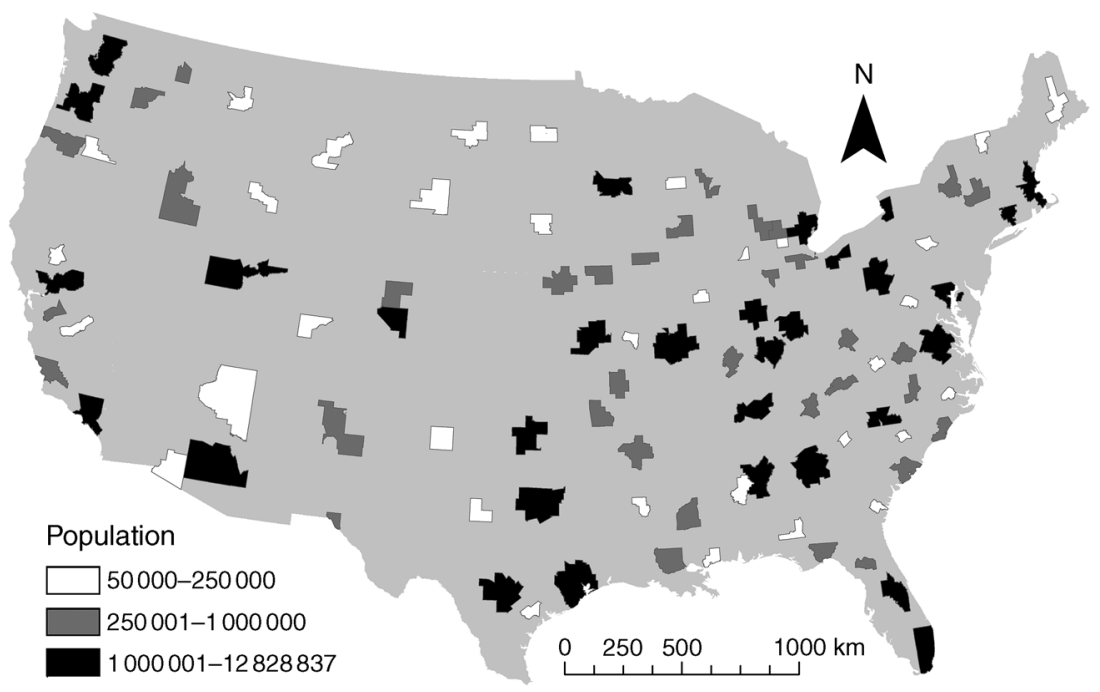

FIG. 1. Map of the conterminous United States with the 100 selected metropolitan statistical areas (MSA) categorized by population.

United States Office of Management and Budget defines a metropolitan statistical area by an urban core with population of at least 50000 , and the associated counties with a high degree of social and economic integration (as measured by commuting to work) with the urban core (Census Bureau 2012). To ensure a representative sampling, cities were categorized by population (three groups) and by their designated ecological regions as established by the National Ecological Observatory Network (NEON; Fig. 1). These ecological regions are based on vegetation, landforms, climate, and ecosystem performance (NEON 2010). The number of metropolitan statistical areas selected from each ecological region was weighted based on the proportion present. Metropolitan statistical areas were hand selected to be representative of the population and geographically distributed across an ecological region. Cities located on the border between two regions were classified as the region with the majority of land area.

To characterize the land cover, we calculated the majority land cover for each census block group within the metropolitan statistical area using the 2006 National Land Cover Data (NLCD) and ArcGIS (v10) (Fry et al. 2011). The Zonal Statistics function was used to calculate the number of cells for the cover type within each census block group and determine the majority land cover. Water is a coverage category in the NLCD, and for a small number of census block groups in some cities, water was calculated as the majority land cover. The majority non-water land cover was assigned to these census block groups by hand, based on the NLCD of the surrounding census block groups. The NLCD classes were grouped into five categories: urban open area $(\mathrm{NLCD}=21)$, urban low intensity $(\mathrm{NLCD}=22)$, urban medium intensity $(\mathrm{NLCD}=23)$, urban high intensity $(\mathrm{NLCD}=24)$, agriculture $(\mathrm{NLCD}=81,82)$, and "undeveloped" (all remaining NLCD). NLCD categories are based on the percentage of impervious surface area and the land use. Urban open area land cover includes parks, golf courses, and other spaces that are developed (i.e., the natural vegetation removed/altered), but not necessarily built up. Low-intensity land cover included residential single-family homes and other lowdensity development. Medium-intensity development includes multi-family residential development and some business districts. High-intensity development includes industrial and other highly developed areas. The undeveloped category includes regions designated as forest, scrub, or desert, depending on the region and climate. We recognized that this designation does not necessarily mean the region exists in an unaltered state, but provides the most reasonable comparison for how urbanization has changed water bodies.

\section{Water body classification}

Data on surface water features in each metropolitan statistical area were acquired from the National Hydrography Dataset (NHD) (USGS 2012). Features included water bodies (i.e., lakes/ponds, reservoirs, swamps/marshes) and surface flow lines. The national coverage of high-resolution data was produced at a maximum scale of 1:24000. We recognized that the number of missing stream channels may be as high as $78 \%$ at this scale (Roy et al. 2009, Benstead and Leigh 2012). There is no known estimate of missing water bodies (lakes, ponds, reservoirs, and wetlands), but the quality of coverage is assumed to be satisfactory for water bodies as small as $0.001 \mathrm{~km}^{2}$ (McDonald et al. 2012). We are aware of no evidence that water body errors of omission are greater in urban compared to rural landscapes. 

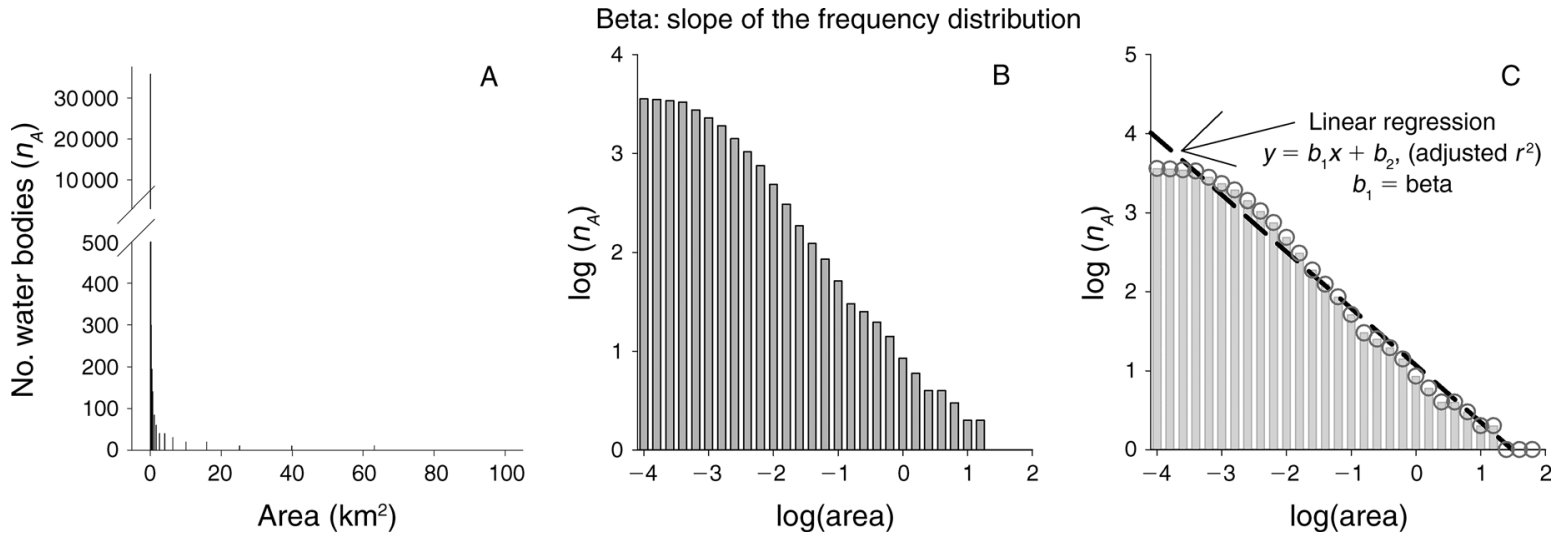

FIG. 2. Example of the calculation of the size frequency distribution parameters. (A) The number of water bodies with area greater than area $A\left(n_{A}\right)$ follows a distribution similar to the Pareto distribution. Note the break in the $y$-axis. (B) Log transforming both the number of water bodies and the area linearizes the distribution. (C) Fitting a linear regression model to the logtransformed frequency distribution provides a measure of the relative distribution of small to large water bodies (slope, $\left.b_{1}\right)$ and an estimate of how well the distribution conforms to the ideal Pareto distribution (adjusted $r^{2}$ ).

The hydrography data layers were intersected with the land cover layer to determine the type, number, area, and length of water features within each land cover category. Water bodies that crossed the boundary of two land cover categories were divided. However, the number of water bodies that were bisected was small compared to the total number of water bodies in each metropolitan statistical area. For the undeveloped land, we used the NHD feature point data to locate all of the water bodies with dams in the undeveloped land class (though not all impoundments are included in this estimate). Because these water bodies are obviously not naturally occurring, the impounded water bodies were not included in the undeveloped land class.

\section{Data analysis}

Water bodies were characterized by calculating metrics described below for size, shape, connectivity to surface flow lines, as well as the water body type/ function based on NHD designations (Feature Codes). NHD classifies water bodies into numerous categories that were consolidated into (1) perennial lakes and ponds, (2) intermittent/ephemeral water bodies, (3) perennial swamps and marshes, (4) reservoirs for water storage, and (5) reservoirs for other functions (for example, wastewater treatment ponds). NHD defines a reservoir as a "constructed basin," which includes water bodies such as waste water treatment and aquiculture ponds. Reservoirs, under the NHD definition, are differentiated from water bodies formed by impoundments which still have predominantly natural shorelines. The latter are still categorized as lakes/ponds despite being "man-made" and commonly called reservoirs.

To characterize the size of water bodies within land cover classes, we compared the parameters of the frequency distribution of water body sizes following the methods of Downing et al. (2006) and Seekell and Pace (2011). The frequency of water body sizes generally follows a distribution similar to the Pareto distribution, with very large numbers of small water bodies and few very large water bodies (Fig. 2A). When both the area $(A)$ and number of water bodies equal to or greater than size $A\left(n_{A}\right)$ are $\log _{10}$ transformed, the ideal Pareto distribution is linear (Fig. 2B). Fitting a linear regression model to the log-transformed distribution provides two parameters with which different distributions can be compared: the slope $\left(\beta_{\text {size }}\right)$, and the coefficient of correlation $r^{2}$ (Fig. $2 \mathrm{C})$. The $\beta_{\text {size }}$ is always negative and describes the relative proportions of small to large water bodies; the more negative (i.e., steeper) the slope, the greater the relative proportion of small to large water bodies. The $r^{2}$ of the regression provides a measure of how closely the distribution of water body sizes conforms to the Pareto distribution; the closer $r^{2}$ is to 1, the better the fit (Seekell and Pace 2011, Seekell et al. 2013).

We examined the shape of lakes using the shoreline development factor (SDF), a commonly used measure of tortuosity. SDF calculates an index of irregular shape by comparing each lake to a perfect circle based on its area and perimeter length

$$
\mathrm{SDF}=\text { shape length } /(2 \times \sqrt{\pi \times \text { shape area }}) .
$$

The SDF approaches 1 as the shape becomes closer to a perfect circle, and increases as the tortuosity of the shoreline increases. Using a similar evaluation as water body size, we calculated both the median SDF for each city and the slope of the log-log transformed SDF frequency distribution to evaluate changes in water body shape with land cover.

The connectivity of water bodies to surface flow lines (i.e., streams and rivers) was measured by intersecting the water body with the flow lines buffered with a $10 \mathrm{~m}$ radius to account for minor variation in the position of flow lines that occur at the 1:24000 resolution. Connectivity was then calculated as a percentage of 

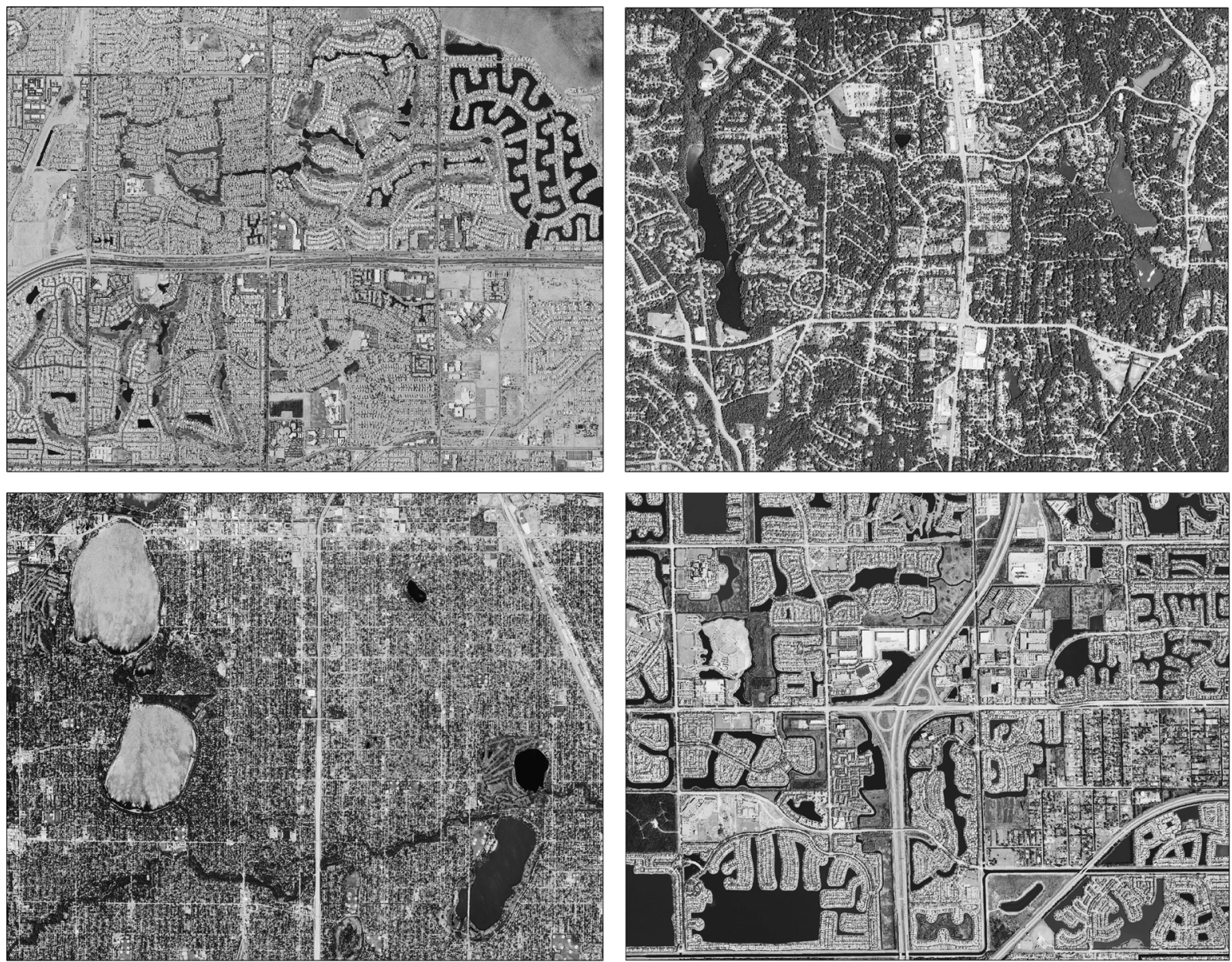

PLATE 1. Some of the studied lakes and ponds in the metropolitan statistical areas (MSAs) selected in the United States: (upper left) Phoenix, Arizona; (upper right) Raleigh, North Carolina; (lower left) Minneapolis, Minnesota; and (lower right) Miami, Florida. Aerial imagery courtesy of the USDA FSA.

water bodies connected to flow lines in each land cover and size class.

We compared the size, shape, and connectivity of land cover classes with a univariate analysis of variance and Tukey's post hoc mean comparison. Cities were also divided into three groups to evaluate differences across precipitation regimes and population sizes. IBM SPSS v20 (IBM SPSS 2011) was used for all statistical procedures.

\section{Results}

\section{Land cover}

The total land area included in this study was 991274 $\mathrm{km}^{2}$, which is $\sim 11 \%$ of the land area in the contiguous United States. The footprint of the metropolitan statistical areas ranged from 1537 to $48332 \mathrm{~km}^{2}$, with a median of $7803 \mathrm{~km}^{2}$. Land cover composition, as computed by the majority census block group method, varied across the metropolitan statistical areas, but the undeveloped land frequently comprised the largest percentage, with 70 metropolitan statistical areas having
$50 \%$ or greater undeveloped land cover (Fig. 3A). Only a few metropolitan statistical areas $(n=3)$ had no census block groups whose majority cover was undeveloped land; all nonurban land in these cities was categorized as agriculture. The agricultural land cover in the metropolitan statistical areas ranged from $0 \%$ to $98 \%$, with a median of $24 \%$. Urban land cover comprised the smallest percentage of land area, ranging from $40 \%$ to $<1 \%$, with 49 cities having an urban area of $250 \mathrm{~km}^{2}$ or less.

The proportion of urban land classes (open area and low, medium, and high intensity) also varied among the 100 cities (Fig. 3B). Low-intensity urban land had the largest coverage in most cities, with a median coverage of $48 \%$ of the urban land; 81 cities had at least $30 \%$ of the urban land area in this class. Urban open-area land cover was the next most prevalent land cover, with a median coverage of $28 \%$ of the urban land area. Medium- and high-intensity land covers were generally smaller components of the urban matrix across all 100 cities, with medians of $10 \%$ and $2 \%$, respectively. However, their coverages ranged from $0 \%$ to $69 \%$ and $0 \%$ to $37 \%$ of the urban land area among cities. Of the 
A) MSA land cover composition

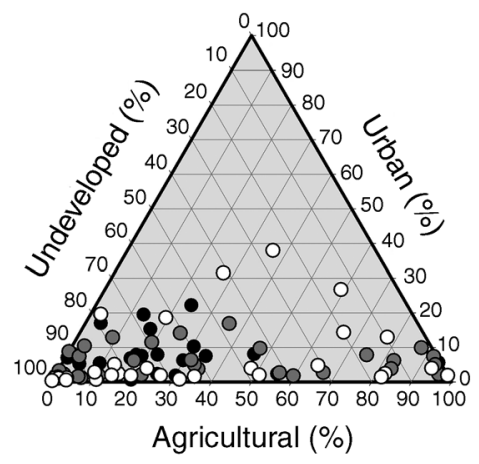

Population size

- Large

o Medium

oSmall
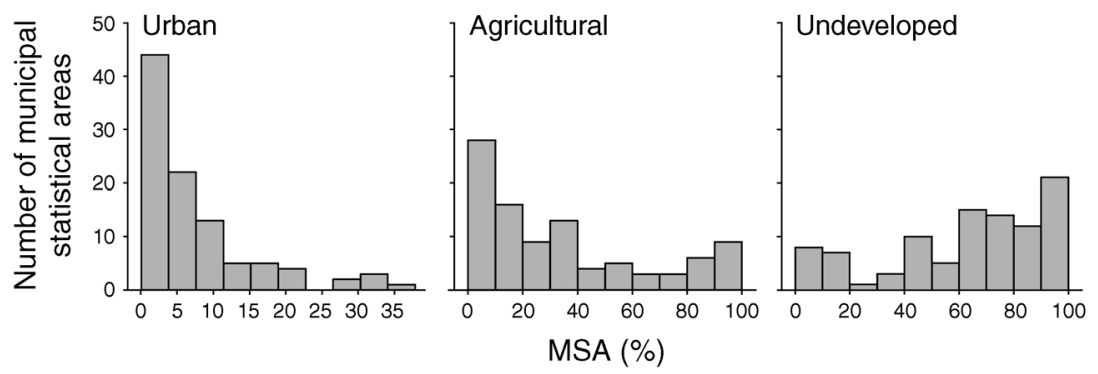

\section{B) Urban land cover composition}
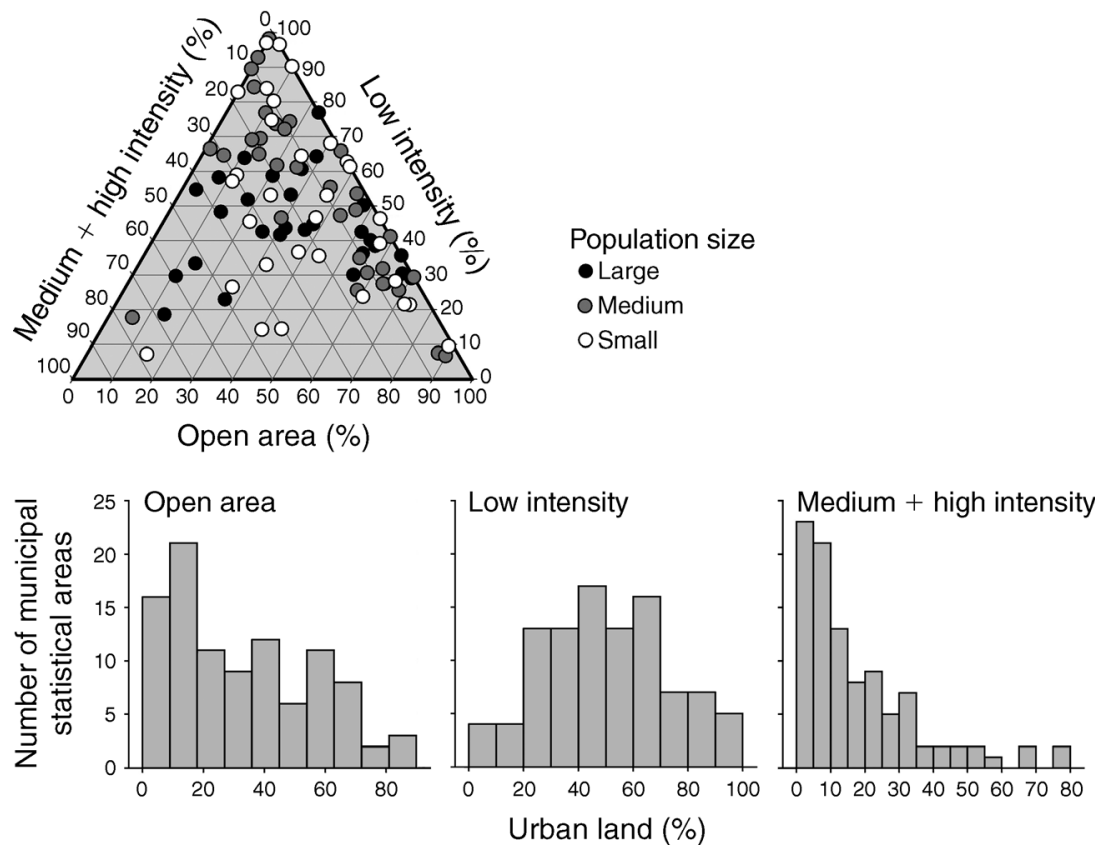

FIG. 3. The composition of land cover in 100 metropolitan statistical areas (MSA) in the United States. (A) Percentage of undeveloped, agriculture, and urban land cover in each MSA. (B) Proportion of urban open area, low-intensity, and medium + high-intensity land cover in the urban land of each city.

100 cities, 12 cities had no medium-intensity and 43 had no high-intensity urban land cover. If those cities are removed from the calculation, the median land cover increases to $12 \%$ and $4.6 \%$ for medium- and highintensity land covers, respectively.

\section{Water body classes}

Lakes and ponds were the dominant type of water body in all land cover and city size classes (Fig. 4A-C; note $y$-axis is on a logarithmic scale). Water bodies in small cities (250 000 people or fewer) were almost 


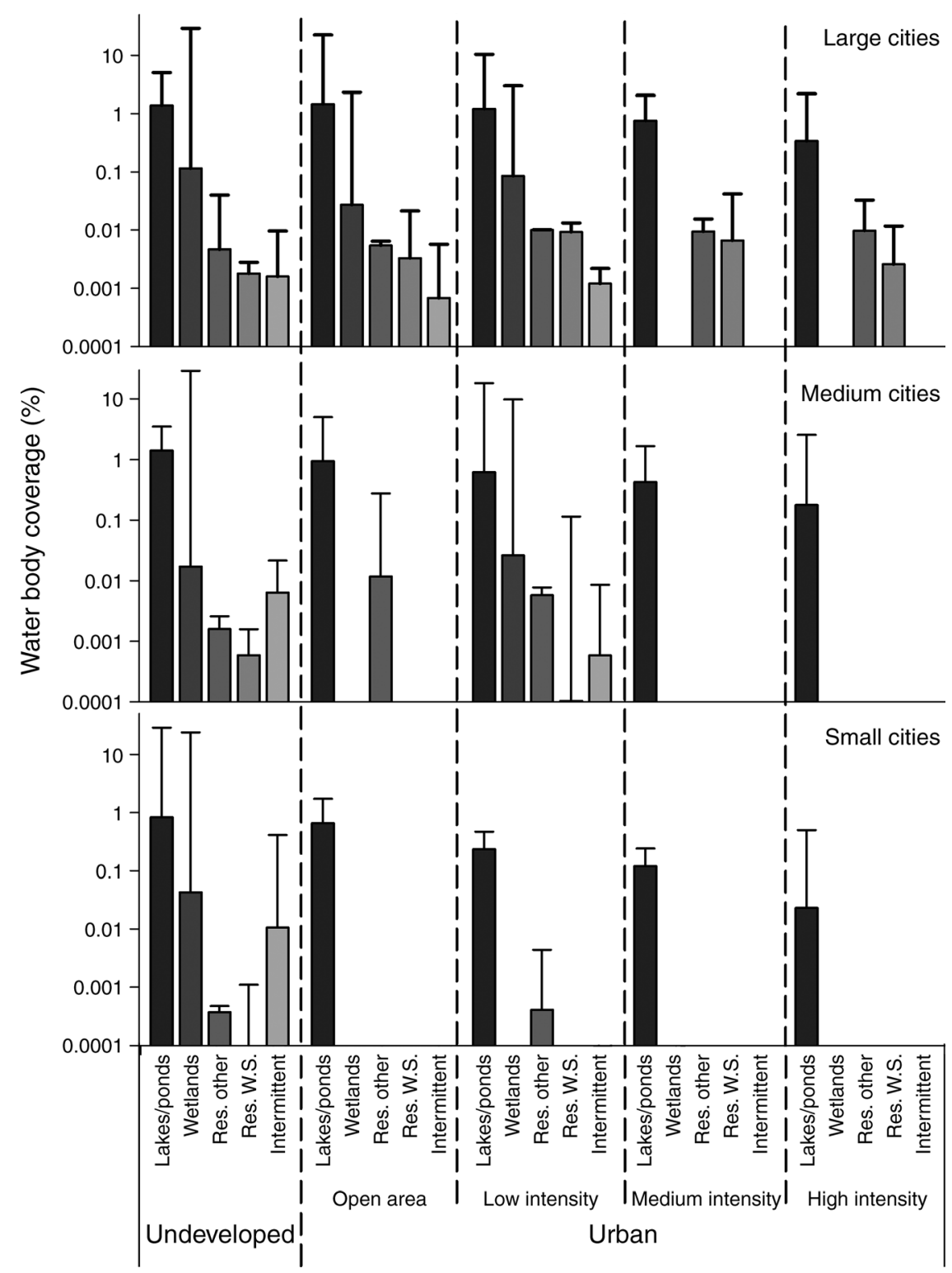

FIG. 4. The median proportion of total area covered by surface water of each classification type (perennial lakes and ponds [Lakes/ponds], wetlands, reservoirs, water storage [Res. W.S.] and other [Res. other], intermittent water bodies [Intermittent]) in different land covers varies as a function of city size. Land covers range from undeveloped to open area urban, through low-, medium-, and high-intensity development. Whiskers represent the $75 \%$ quartile. Note logarithmic scale on $y$-axes.

exclusively lakes and ponds. Wetlands (swamps and marshes) were the next largest group in the undeveloped land cover. In large cities (population $>1$ million people), low-intensity land cover had a similar proportion of swamps and marshes as was observed in undeveloped land; smaller coverages were observed in the open-area land cover. Medium cities had much smaller areas of wetlands than did large cities, and small cities had essentially none. For all city sizes, wetlands were sparse in medium- and high-intensity land covers. Water storage and other functional reservoirs were found in all four urban intensity classes in large cities, but increased in proportion relative to other types of water bodies with development intensity. In mediumsized cities, these functional water bodies were only found in the open and low intensity. These types of water bodies were exceedingly rare in all urban land cover classes of small cities.

\section{Water body size and shape}

As the intensity of urban land cover increased, the relative proportion of small water bodies decreased. The slope of the size distribution $\left(\beta_{\text {size }}\right)$ of urban water bodies was significantly less negative (shallower) than $\beta_{\text {size }}$ of 

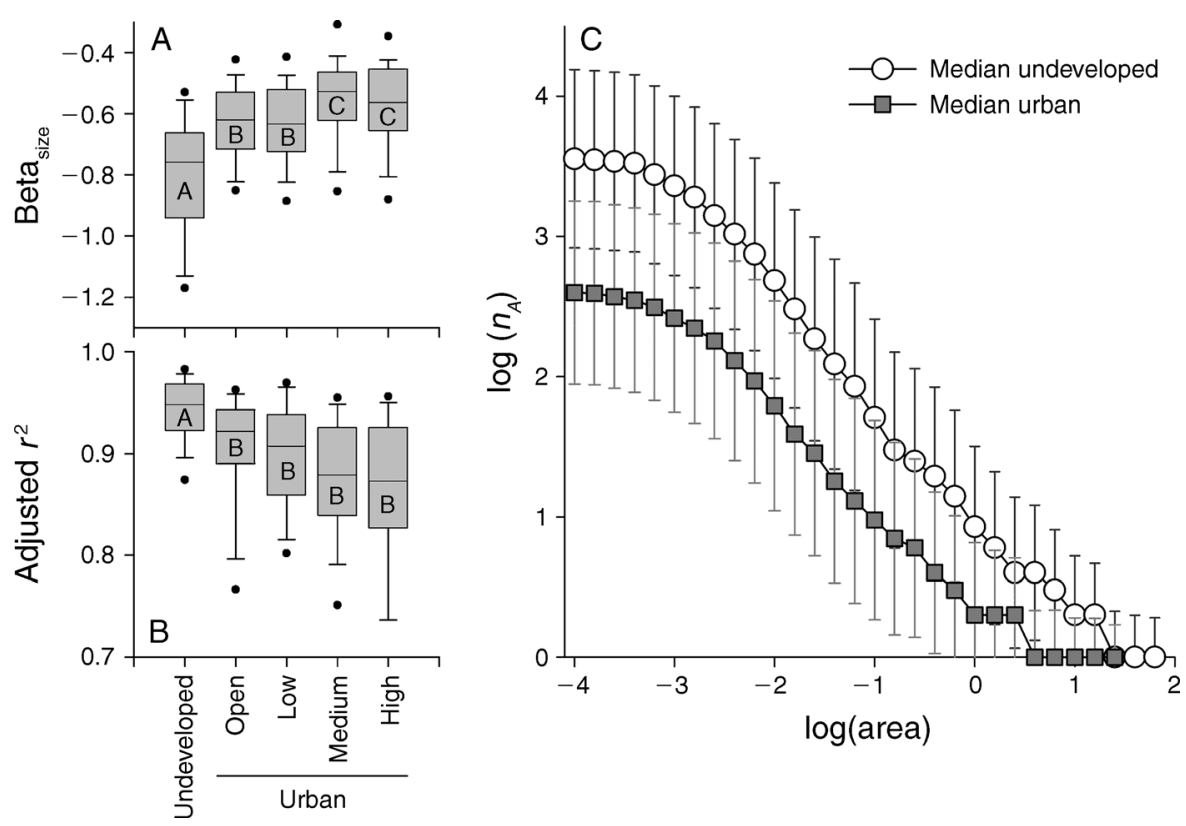

FIG. 5. Size distributions of lakes in urban and undeveloped land indicate preferential absence of small water bodies in urban land. (A) The slope and (B) adjusted $r^{2}$ of the size frequency distribution (Beta size $_{\text {) }}$ of the six land cover categories (undeveloped, urban open area, low-intensity urban, medium-intensity urban, and high-intensity urban) indicates that the bias in size distributions toward large water bodies increases with urban development. For the box plots, the center line is the median (Q2); the bottom and top of the box are the 25th and 95th percentiles, respectively; whiskers are the 10th and 90th percentiles; the black dots are the 5th and 95th percentiles. Capital letters within the boxes indicate significant differences at $P<0.05$. (C) In the log of abundance $\left(n_{A}\right)$ vs. $\log$ (area) plot for undeveloped and urban land classes, the points represent the median abundance across all cities in that size class, and bars represent \pm SD. While all sizes of water bodies are less abundant in urban land, the gap in abundance is greater for small than for large water bodies.

water bodies in the undeveloped land cover, indicating a shift in the distribution toward larger water bodies (Fig. 5A). This shift increased with development intensity, so that the medium- and high-intensity urban land covers had the greatest increase in the distribution of water body sizes.

The fit of the data to the Pareto distribution, as measured by the $r^{2}$ of the log-linear regression, also decreased with development intensity (Fig. 5B). The size distribution of water bodies in the undeveloped land had the best fit, while the high-intensity urban land cover had the poorest fit to the Pareto distribution. Although the $r^{2}$ could quantitatively estimate deviation of the ideal distribution, it cannot estimate the nature of the deviation. Visual observation of the median undeveloped and urban distributions indicated that the distributions were roughly parallel except for the smallest water bodies $(<0.5 \mathrm{ha})$, where the shape of the urban distribution deviated from that of the undeveloped distribution (Fig. 5C). This suggests that differences in size distributions reflect underrepresentation of the smallest water bodies in urban landscapes.

Water body shape, as measured by the SDF, was marginally influenced by land cover. The median SDF indicated a significant increase in the shoreline-to-area ratio in the urban low-, medium-, and high-intensity land cover classes, meaning that urban water bodies are likely to be longer and tortuous compared to the undeveloped land (Fig. 6A). The variation in median SDF across cities increased at medium- and highintensity urban land covers. In contrast, the slope of the SDF frequency distribution was significantly lower in high-intensity urban land cover than undeveloped land, indicating that the distribution was shifting to "rounder" water bodies in these land covers (Fig. 6B).

\section{Water body connectivity}

Significantly fewer water bodies in the urban land covers were connected to surface flow lines (i.e., streams and rivers) compared to water bodies in undeveloped land. The median connected water body area fell from $83 \%$ in the undeveloped land cover to $18 \%$ in the highintensity urban land cover (Fig. 7). The median number of connected water bodies fell from $40 \%$ in the undeveloped land to $10 \%$ in the high-intensity urban land cover. In the undeveloped land cover, precipitation regime did not affect the proportion of water bodies connected to surface flow lines; however, in urban land covers, greater reductions in connectivity were observed in dry regions (Fig. 7). Although the percentage of water bodies connected to surface flow lines increased as the size of water bodies increased, small water bodies $(<0.01$ $\mathrm{km}^{2}$ ) in urban land covers were more likely to be 


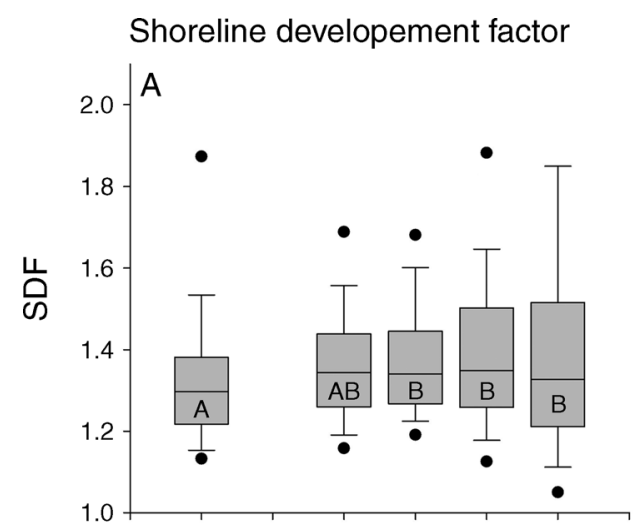

Shape classes

C
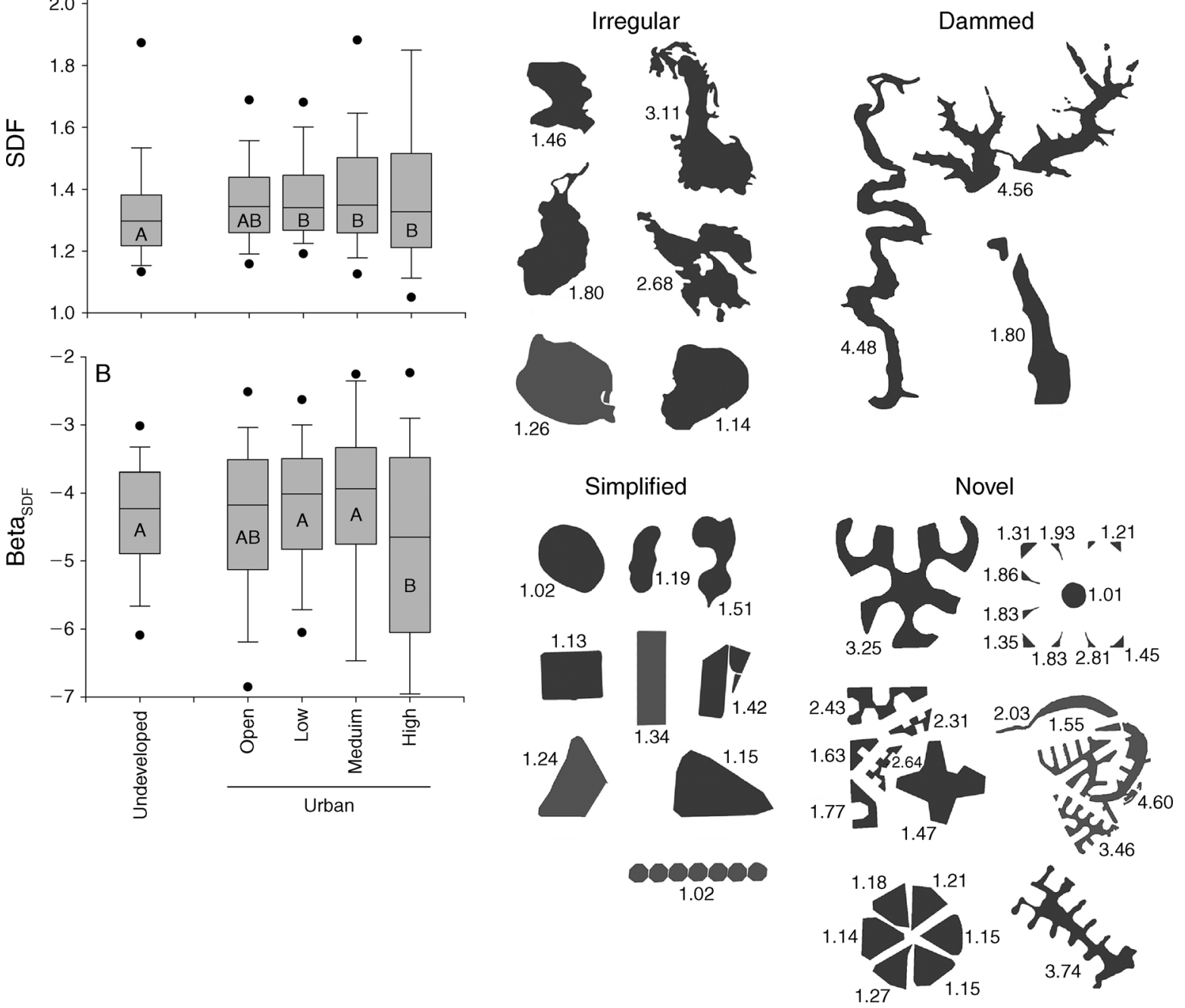

FIG. 6. Shapes of urban lakes. (A) The median shoreline development factor (SDF) of water bodies in land cover classes of the 100 cities, and (B) the slope of the frequency distribution (BetasDF) of the SDF for each land cover. See Fig. 5 caption for identification of box plots. Capital letters denote significant differences at $P<0.05$. (C) Examples of water body shape in four classes: irregular spheroid, impounded, simplified, and novel. The SDF is noted next to each example.

disconnected from flow lines than similar-sized water bodies in the undeveloped land covers (Fig. 8).

\section{DisCUSSION}

Urban water bodies differed from water bodies in undeveloped land in all measured characteristics: type composition, size, shape, and connectivity to surface flow lines. Although there is substantial variability across the 100 cities we surveyed, the greatest differences were consistently observed in the most intensely developed urban land. In addition, within a land cover class the differences in water body characteristics were not related to the population of cities, except for the composition of water body types. Low-intensity urban land cover in small, medium, and large cities, for example, had the same effect on water body size, shape, and connectivity. The differences between the characteristics of urban and undeveloped water bodies provide insights into how urbanization changes water bodies and landscape-scale hydrographic structure; these differences also have implications for biogeochemistry and ecosystem function.

\section{Mechanisms leading to hydrographic differences}

Water bodies in urban land covers tend to be of more moderate size and less connected than those in undeveloped land. The differences in the size distributions suggest that the smallest water bodies $(<0.5 \mathrm{ha})$ are the most affected by urbanization. These changes occur concurrently with changes in areal water body coverage 


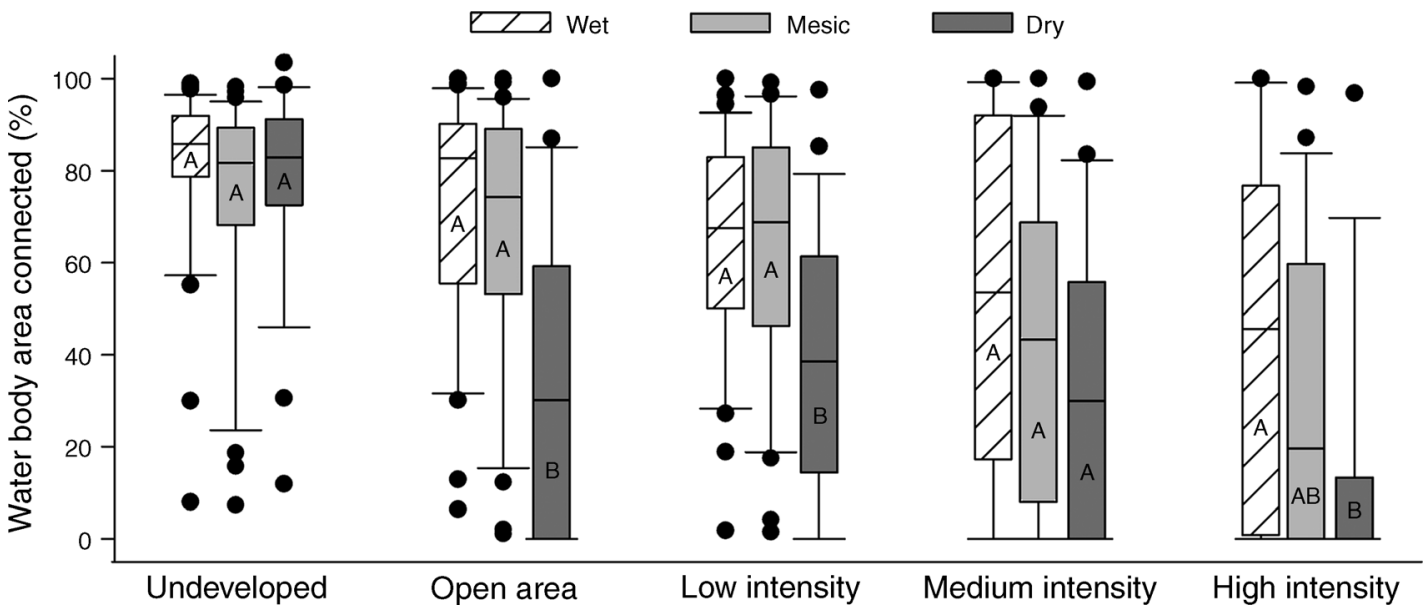

FIG. 7. Connectivity of urban water bodies. The percentage of water body area that intersects surface flow lines in the land cover classes is shown. Groups are further divided into three precipitation groups: wet $(>1100 \mathrm{~mm})$, mesic $(700-1100 \mathrm{~mm})$, and dry $(<700 \mathrm{~mm})$. See Fig. 5 caption for identification of box plots. The black dots represent each datum above the 90 th or below the 10th percentile. Capital letters above the bars designate significant differences $(P<0.05)$ between wet, mesic, and dry connectivity within a land cover class.
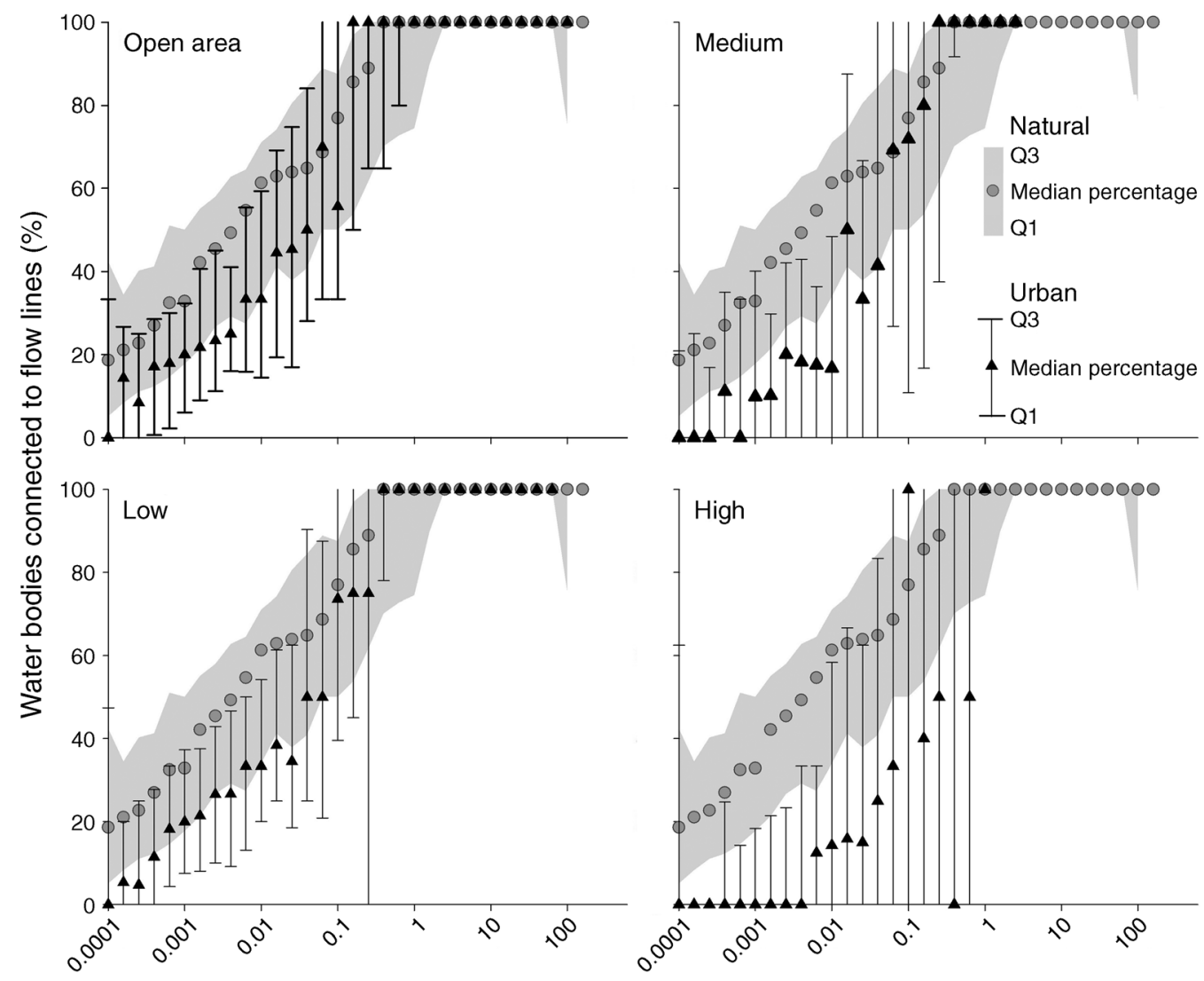

\section{Water body size class $\left(\mathrm{km}^{2}\right)$}

FIG. 8. The percentage of water bodies connected to flow lines (streams, rivers, channels) in each size class. The median percentage of connected natural water bodies of the 100 metropolitan statistical areas (gray circles) is represented in all four panels. The median percentage of connected water bodies in the urban open area, and urban low-, medium-, and high-intensity land covers are represented by black triangles. The gray area (natural) and black bars (urban) represent the first (Q1) and third (Q3) quartiles. Note the logarithmic scale on the $x$-axis. 
(Du et al. 2010, Larson and Grimm 2011, Steele et al. 2014).

The extent to which urban water bodies reflect prior agricultural development is unknown; however, the size, shape, and connectivity of water bodies in the agricultural land of this study display opposite trends, with smaller and rounder water features (M. K. Steele, unpublished data). An agricultural legacy effect may be more prominent in the hinterland of cities in certain regions. However, because urbanization and agriculture display opposing trends in water body size distributions, it seems unlikely that agricultural legacies are a major mechanism shaping urban water bodies. Potential mechanisms responsible for changing the size distribution of urban water bodies include: preferential removal, physical reshaping or addition of water bodies that meet aesthetic or functional preferences, and selection of locations for development with water bodies of certain morphological properties.

The preferential drainage or removal of small water bodies from cities likely contributes to changes in water body size distributions. Studies have documented the intentional removal or loss of water features from urban landscapes, and evidence from studies on stream burial in cities indicates these practices preferentially remove small headwater streams (Trimble 2003, Elmore and Kaushal 2008, Roy et al. 2009, Du et al. 2010). Our data also indicate that the smallest water bodies are the most affected by urbanization; however, a case study from Wuhan, China, found that nearly all water bodies were altered during urbanization, including the fragmentation of large water bodies (Du et al. 2010). Plausibly, an urban water body must be of moderate size before (a) its recreational or aesthetic value equals that of the alternative land uses, or (b) the cost of draining it exceeds the value of the alternative use. Alternatively or in addition, local and regional policies may be preferentially preserving the largest features in the landscape.

The addition of water bodies by construction and the reshaping of existing water bodies may also contribute to the differences in size distributions. Cities with naturally minimal surface water abundance tend to add water bodies to the urban landscape (Larson and Grimm 2011, Steele et al. 2014). A study of water bodies in Phoenix, Arizona, USA, identified artificial lakes in the metropolitan region and reported that their mean area ranged from 0.6 to 0.9 ha (Larson and Grimm 2011), just larger than the $\leq 0.5$-ha size range our data suggest is underrepresented. Artificially constructed and impounded lakes and ponds embody human preferences regarding water bodies and the methods used to construct them (see Plate 1).

Specific alterations (construction, impounding) usually result in characteristic changes to the shape of water bodies. For example, impounded streams and rivers have the classic dendritic shape, with elongated tendrils and a single linear edge, and simplified water body shapes are associated with urban activities (Hwang et al.
2007). Hwang et al. (2007) observed that urban land cover simplified the shape of reservoirs, and that the simplification of the shoreline also correlated with decreases in oxygen demand and phosphorus concentrations. Shape may provide a useful signature of the type and extent of alteration in cities. Using the frequency distribution of shoreline development factor as a shape metric detected some differences in the shape of water bodies in high-density land cover (rounder water bodies). Like all general shape metrics, however, SDF had limited capacity to quantify the wide variety of shapes that we observed (Fig. 6C). Visual observations indicate the majority of water bodies in all land cover classes were irregular spheroids, but certain shapes were associated with human alteration. The impounded dendritic shape was also observed in all land covers. Simplified shapes were primarily observed within urban land cover and were characterized by a reduction of irregularity of the basic shape and a reduction in tortuosity and irregularity of the shoreline. Novel shapes were rarest, and most frequently observed in the openarea and low-intensity land covers of large cities such as Miami, Houston, and Phoenix. Cities like Miami, Houston, and Phoenix are located in regions at the very wet and very dry extremes of the hydrographic gradient, requiring substantial infrastructure to drain water from or add water to the landscape (Larson and Grimm 2011).

Water features have certainly influenced the location and growth of cities throughout the history of urban development, as many major cities are located along rivers, coastlines, or the shores of large lakes (Parkman 1983, Cronon 1992). At a smaller scale, we hypothesize that hydrographic features also influence the decision to develop certain areas within cities. Applying this concept to water body characteristics, we suggest that locations with fewer, larger water bodies may be more conducive to development than areas with numerous, small water bodies, and therefore contribute to the bias in the distribution of water body sizes toward larger areas. Alternatively, the preference for locating cities in regional lowland and on flatter land, such as that found in floodplain terraces, also may select for a certain character of water bodies.

The role of these three mechanisms (preferential removal, addition/reshaping, development location) in shaping hydrographic characteristics likely depends on the initial hydrographic conditions and the size and age of cities. To evaluate the effects of urbanization on such a broad scale, it was necessary to substitute space for time, and we recognize our ability to infer a temporal change from spatial differences is limited. However, different city sizes provide one lens through which to understand how the mechanisms shaping hydrography of cities may change with time. Small cities, we assume, are more representative of an initial footprint of cities, while large cities have certainly expanded beyond the initial boundaries of the settlement. This assumption 
allows us to draw some inference about trajectories of change with urban expansion.

The smallest cities had the greatest differences in the distribution of different types of water bodies (i.e., lakes/ ponds, wetlands, etc.) compared to the undeveloped land. Large cities, by comparison, had a type composition that was more similar to its undeveloped counterpart. The lack of wetlands or intermittent water bodies in small cities indicates that either (a) the city was located such that wetlands were avoided, or (b) all wetlands were removed from the city. Because more suitable land is less expensive to develop, we propose that the most desirable areas would be developed before those that needed extensive hydrologic alteration. A similar location selection process may occur as large cities have expanded outward from the original settlement, but eventually the hydrographic features are likely to become an impediment. We hypothesize that the smaller water bodies are removed and moderate and large water bodies become incorporated into the landscape of the city. Location might be more important at initial stages of development, but selective removal would become more important as a city grows. For cities in arid regions, which may be disproportionately sited near water bodies, addition would become a more important mechanism as city area increases. In sum, though population size did not affect the differences in water body characteristics, it may affect which mechanisms are acting over time.

Population size also increases the relative proportion of high and medium land covers. Water body size, shape, and connectivity in the medium- and highintensity urban land covers had the greatest differences from the undeveloped land cover. However, these land covers made up the smallest percentages of most cities. Therefore, urbanization's most acute impacts on water characteristics are likely observed in a relatively small area of land. The ex-urban and sub-urban expansion of recent decades converted large areas to open and lowintensity land cover (Lubowski et al. 2006). Consequently, though differences in water body form may be smaller in open areas and low-intensity land cover, the collective impact of smaller changes across a greater area may have greater importance than the acute impact of the medium and high land covers.

\section{Size, shape, and connectivity: implications for ecosystem function}

The morphological changes in urban water bodies may have consequences for conditions in surrounding terrestrial environments and macroscale biogeochemical cycling. Among other effects, urban water bodies mediate local microclimates (Sun and Chen 2012, Sun et al. 2012). Sun and Chen (2012) found that small water bodies cooled the surrounding landscape more efficiently than large water bodies per unit area, although larger water bodies were associated with greater cooling intensities. In addition, they found that more compactly shaped water bodies (i.e., more square or round) intensified the cooling effect (Sun and Chen 2012). The reincorporation of small water bodies may present an opportunity to mitigate the urban heat island and simultaneously influence biogeochemical cycling on a regional level. Depending on the waste treatment system, urban watersheds export 3-90\% of the nitrogen inputs to the watershed (Bernhardt et al. 2008). Increased inputs and the decoupling of urban riparian zones (Groffman et al. 2002) and other terrestrial routes for retention and removal of nitrogen puts added pressure on the within-flow network to remove N. Small water bodies are more efficient processors, with higher rates of retention and sequestration of carbon and nitrogen (Dean and Gorham 1998, Groffman et al. 2002, Downing et al. 2008, Harrison et al. 2008). The decrease in connectivity to the greater watershed and the loss of the smallest water bodies together may have substantial implications for both the terrestrial environment and regional and global nutrient and carbon cycling.

Small water bodies in urban landscapes are less likely to be connected to streams than in minimally developed landscapes, and patterns of connectivity between lakes and streams reflected an interaction between land use intensity and climate. Case studies also find a reduction in the connectivity of urban water bodies to surface water networks (Cao 2005, Du et al. 2010). These patterns are also consistent with the substantial loss of small urban streams (Elmore and Kaushal 2008, Roy et al. 2009). It is important, however, to reiterate that the flow line data used here to measure connectivity does not include very small, intermittent, and ephemeral streams and those transformed into stormwater drains. Therefore, while we believe, and case studies support, that the decreased connectivity of urban water bodies is a real phenomenon, the lack of high-resolution data at large scales and underrepresentation of human-built surface flowpaths increases the uncertainty of the exact values and should be interpreted cautiously. Urban water bodies may be more connected to their watersheds through pipes, storm drains, and constructed channels not accounted for by our characterization of flow lines. As suggested with urban streams (Kaushal and Belt 2012, Somers et al. 2013), storm water outlets, pipes, buried streams, and other built infrastructure should be considered when evaluating the interactions between urban water bodies and the catchments that supply them. Likewise, we are unable to measure the hydrologic connectivity of water bodies to shallow water tables using these data, but the lining associated with constructed urban water bodies to prevent leaching of water into the ground water would further reduce the connectivity to the greater watershed. Further investigation of connectivity between streams, water bodies, and gray infrastructure is needed given 
the critical role of landscape connectivity for local- and regional-scale processes.

The potential decrease in connectivity of these water bodies to surface flow represents a substantial change in the nature and possibility of interaction between these water bodies and their surrounding watersheds. Lakes in watersheds with low transport capacity of water and nutrients are more reliant on in-lake processes and nearby land cover changes (Fraterrigo and Downing 2008). Though watershed size generally increases with the size of the water body (Nõges 2009), the sensitivity to watershed processes changes, and large water bodies are more dependent on internal processes and dynamics (Genkai-Kato and Carpenter 2005). A recent study of stormwater retention ponds found the role of internal processes was substantial in carbon cycling (Williams et al. 2013). Together, a lack of connectivity to flow lines and the relative increase in sizes suggest that urban water bodies may be decoupled from watersheds at some time scales, with internal and local terrestrial processes playing a larger role in functional dynamics.

A variety of studies suggest that the individual characteristics and landscape-scale spatial structure of water bodies influence the population and community dynamics of aquatic ecosystems. For example, the distribution of macrophytes in southern Swedish lakes depends on both lake characteristics (size, elevation) and connectivity to upstream lakes via stream networks (Dahlgren and Ehrlen 2005). Similarly, spread of nonnative Daphnia in Missouri (United States) lakes depends on between-lake distances within landscapes (Havel et al. 2002). The consequences of connectivity for community composition depend on life history strategies (Beisner et al. 2006), and spatial constraints differ in isolated and connected aquatic environments (Shurin et al. 2009). The alteration of water body density, size, and shape in urban landscapes is thus likely to affect ecological communities irrespective of other changes associated with urban development.

\section{Conclusions: toward an urban pond syndrome?}

This analysis of over one million water bodies indicates urban water bodies collectively have a different morphology than water bodies in undeveloped landscapes. Size, shape, and connectivity were increasingly different as the urban development intensified, resulting in an underrepresentation of small water bodies and a greater abundance of disconnected features. City size, as measured by the population, did not affect the observed trends indicating that a similar water body form is found across cities, but did have type compositions that varied across the size classes. While urban water bodies undoubtedly differ from those in undeveloped lands because of the effects of surrounding land use, their dynamics at some temporal scales may be less coupled to those of the uplands because of greater size, altered shape, and reduced surface connectivity. A complete conceptualization of the structure and function of urban water bodies ("urban pond syndrome") will require a better understanding of how biogeochemical and ecological processes respond to the characteristic size, shape, connectivity, and type of urban water bodies, as well as a range of surrounding land development intensities. Better understanding of the interactions among these characteristics is needed for better management of the complex urban hydrosphere that encompasses streams, rivers, water bodies, and groundwater, as well as the built hydrosystem.

\section{ACKNOWLEDGMENTS}

We thank the Urban Homogenization Group, the Duke River Center, Allison Appling, and the anonymous reviewers for helpful comments on earlier drafts of the manuscript. This research was supported by grants from the National Science Foundation's Macrosystems Biology program (NSF EF No.1065785).

\section{Literature Cited}

Alvo, R., D. J. T. Hussell, and M. Berrill. 1988. The breeding success of common loons (Gavia immer) in relation to alkalinity and other lake characteristics in Ontario. Canadian Journal of Zoology 66:746-752.

Bastviken, D., J. J. Cole, M. L. Pace, and L. J. Tranvik. 2004. Methane emissions from lakes: dependence of lake characteristics, two regional assessments, and a global estimate. Global Biogeochemical Cycles 18:1-12.

Beisner, B. E., P. R. Peres-Neto, E. S. Lindstrom, A. Barnett, and M. L. Longhi. 2006. The role of environmental and spatial processes in structuring lake communities from bacteria to fish. Ecology 87:2985-2991.

Benstead, J. P., and D. S. Leigh. 2012. An expanded role for river networks. Nature Geoscience 5:678-679.

Bernhardt, E. S., L. E. Band, C. J. Walsh, and P. E. Berke. 2008. Understanding, managing, and minimizing urban impacts on surface water nitrogen loading. Annals of the New York Academy of Sciences 1134:61-96.

Birch, S., and J. McCaskie. 1999. Shallow urban lakes: a challenge for lake management. Hydrobiologia 395/396:365-377.

Cao, X. 2005. Landscape pattern dynamics of water body in Kaifeng city in the 20th century. Journal of Geographical Sciences 15:106.

Census Bureau. 2012. Metropolitan and micropolitan statistical areas. http://www.census.gov/population/metro/

Céréghino, R., J. Biggs, B. Oertli, and S. Declerck. 2007. The ecology of European ponds: defining the characteristics of a neglected freshwater habitat. Hydrobiologia 597:1-6.

Cole, J. J., Y. T. Prairie, N. F. Caraco, W. H. McDowell, L. J. Tranvik, R. G. Striegl, C. M. Duarte, P. Kortelainen, J. A. Downing, J. J. Middelburg, and J. Melack. 2007. Plumbing the global carbon cycle: integrating inland waters into the terrestrial carbon budget. Ecosystems 10:172-185.

Crisman, T. L., L. J. Chapman, and C. A. Chapman. 1998. Predictors of seasonal oxygen levels in small Florida lakes: the importance of color. Hydrobiologia 368:149-155.

Cronon, W. 1992. Nature's metropolis: Chicago and the Great West. W. W. Norton, New York, New York, USA.

Dahlgren, J. P., and J. Ehrlen. 2005. Distribution patterns of vascular plants in lakes-the role of metapopulation dynamics. Ecography 28:49-58.

Davies, B. R., J. Biggs, P. J. Williams, J. T. Lee, and S. Thompson. 2007. A comparison of the catchment sizes of rivers, streams, ponds, ditches and lakes: implications for protecting aquatic biodiversity in an agricultural landscape. Hydrobiologia 597:7-17. 
Dean, W. E., and E. Gorham. 1998. Magnitude and significance of carbon burial in lakes, reservoirs, and peatlands. Geology 26:535.

De Bie, T., S. Declerck, K. Martens, L. De Meester, and L. Brendonck. 2007. A comparative analysis of cladoceran communities from different water body types: patterns in community composition and diversity. Hydrobiologia 597:19-27.

Dodson, S. I., R. A. Lillie, and S. Will-Wolf. 2005. Land use, water chemistry, aquatic vegetation, and zooplankton community structure of shallow lakes. Ecological Applications 15:1191-1198.

Dodson, S. I., A. L. Newman, S. Will-Wolf, M. L. Alexander, M. P. Woodford, and S. Van Egeren. 2008. The relationship between zooplankton community structure and lake characteristics in temperate lakes (Northern Wisconsin, USA). Journal of Plankton Research 31:93-100.

Downing, J. A. 2010. Emerging global role of small lakes and ponds: little things mean a lot. Limnetica 29:9-24.

Downing, J. A., J. J. Cole, J. J. Middelburg, R. G. Striegl, C. M. Duarte, P. Kortelainen, Y. T. Prairie, and K. A. Laube. 2008. Sediment organic carbon burial in agriculturally eutrophic impoundments over the last century. Global Biogeochemical Cycles 22:1-10.

Downing, J. A., et al. 2006. The global abundance and size distribution of lakes, ponds, and impoundments. Limnology and Oceanography 51:2388-2397.

Du, N., H. Ottens, and R. Sliuzas. 2010. Spatial impact of urban expansion on surface water bodies - a case study of Wuhan, China. Landscape and Urban Planning 94:175-185.

Dunham, J. B., and B. E. Rieman. 1999. Metapopulation structure of bull trout: influence of physical, biotic, and geometrical landscape characteristics. Ecological Applications 9:642-655.

Eadie, J. M., and A. Keast. 1984. Resource heterogeneity and fish species diversity in lakes. Canadian Journal of Zoology 62:1689-1695.

Effler, S. W., S. M. O'Donnell, A. R. Prestigiacomo, D. M. O'Donnell, R. K. Gelda, and D. A. Matthews. 2010. The effect of municipal wastewater effluent on nitrogen levels in Onondaga Lake, a 36-year record. Water Environment Research 82:3-19.

Elmore, A. J., and S. S. Kaushal. 2008. Disappearing headwaters: patterns of stream burial due to urbanization. Frontiers in Ecology and the Environment 6:308-312.

Fraterrigo, J. M., and J. A. Downing. 2008. The influence of land use on lake nutrients varies with watershed transport capacity. Ecosystems 11:1021-1034.

Fry, J. X., G., S. Jin, J. Dewitz, C. Homer, L. Yang, C. Barnes, N. Herold, and J. Wickham. 2011. Completion of the 2006 National Land Cover Database for the conterminous United States. Photogrammetric Engineering and Remote Sensing 77:858-864.

Genkai-Kato, M., and S. R. Carpenter. 2005. Eutrophication due to phosphorus recycling in relation to lake morphometry, temperature, and macrophytes. Ecology 86:210-219.

Goodman, K. J., M. A. Baker, and W. A. Wurtsbaugh. 2011. Lakes as buffers of stream dissolved organic matter (DOM) variability: Temporal patterns of DOM characteristics in mountain stream-lake systems. Journal of Geophysical Research-Biogeosciences 116:1-15.

Groffman, P. M., N. J. Boulware, W. C. Zipperer, R. V. Pouyat, L. E. Band, and M. F. Colosimo. 2002. Soil nitrogen cycle processes in urban riparian zones. Environmental Science and Technology 36:4547-4552.

Hamer, A., and K. M. Parris. 2011. Local and landscape determinants of amphibian communities in urban ponds. Ecological Applications 21:378-390.
Hanson, P. C., S. R. Carpenter, J. A. Cardille, M. T. Coe, and L. A. Winslow. 2007. Small lakes dominate a random sample of regional lake characteristics. Freshwater Biology 52:814822 .

Harrison, J. A., R. J. Maranger, R. B. Alexander, A. E. Giblin, P.-A. Jacinthe, E. Mayorga, S. P. Seitzinger, D. J. Sobota, and W. M. Wollheim. 2008. The regional and global significance of nitrogen removal in lakes and reservoirs. Biogeochemistry 93:143-157.

Havel, J. E., J. B. Shurin, and J. R. Jones. 2002. Estimating dispersal from patterns of spread: spatial and local control of lake invasions. Ecology 83:3306-3318.

Hwang, S. J., S. W. Lee, J. Y. Son, G. A. Park, and S. J. Kim. 2007. Moderating effects of the geometry of reservoirs on the relation between urban land use and water quality. Landscape and Urban Planning 82:175-183.

IBM SPSS. 2011. IBM SPSS v20. IBM SPSS, Chicago, Illinois, USA.

Jiang, W., W. Wang, Y. Chen, J. Liu, H. Tang, P. Hou, and Y. Yang. 2012. Quantifying driving forces of urban wetlands change in Beijing City. Journal of Geographical Sciences 22:301-314.

Kaushal, S. S., and K. T. Belt. 2012. The urban watershed continuum: evolving spatial and temporal dimensions. Urban Ecosystems 15:409-435.

Kelly, C. A., E. Fee, P. S. Ramlal, J. W. M. Rudd, R. H. Hesslein, C. Amena, and E. U. Schindler. 2001. Natural variability of carbon dioxide and net epilimnetic production in the surface waters of boreal lakes of different sizes. Limnology and Oceanography 46:1054-1064.

Kentula, M. E., S. E. Gwin, and S. M. Pierson. 2004. Tracking changes in wetland with urbanization: sixteen years of experience in Portland, Oregon, USA. Wetlands 24:734-743.

Larson, E. K., and N. B. Grimm. 2011. Small-scale and extensive hydrogeomorphic modification and water redistribution in a desert city and implications for regional nitrogen removal. Urban Ecosystems 15:71-85.

Leavitt, P. R., C. S. Brock, C. Ebel, and A. Patoine. 2006. Landscape-scale effects of urban nitrogen on a chain of freshwater lakes in central North America. Limnology and Oceanography 51:2262-2277.

Lindstrom, M. 2001. Urban land use influences on heavy metal fluxes and surface sediment concentration of small lakes. Water, Air, and Soil Pollution 126:363-383.

Lubowski, R. N., M. Vesterby, S. Bucholtz, A. Baez, and M. J. Roberts. 2006. Major uses of land in the United States. 2002. Economic Information Bulletin No 14. United States Department of Agriculture, Economic Research Service, Washington, D.C., USA.

Marcogliese, D. J., and D. K. Cone. 1991. Importance of lake characteristics in structuring parasite communities of salmonids from insular Newfoundland. Canadian Journal of Zoology 69:2962-2967.

McDonald, C. P., J. A. Rover, E. G. Stets, and R. G. Striegl. 2012. The regional abundance and size distribution of lakes and reservoirs in the United States and implications for estimates of global lake extent. Limnology and Oceanography 57:597-606.

McKinney, R. A., K. B. Raposa, and R. M. Cournoyer. 2011. Wetlands as habitat in urbanizing landscapes: patterns of bird abundance and occupancy. Landscape and Urban Planning 100:144-152.

Meter, R. J., C. M. Swan, and J. W. Snodgrass. 2011. Salinization alters ecosystem structure in urban stormwater detention ponds. Urban Ecosystems 14:723-736.

Meyer, J. L., M. J. Paul, and W. K. Taulbee. 2005. Stream ecosystem function in urbanizing landscapes. Journal of the North American Benthological Society 24:602-612. 
Meyer, J. L., and J. B. Wallace. 2001. Lost linkages and lotic ecology: rediscovering small streams. Pages 295-317 in M. C. Press, N. J. Huntly, and S. Levin, editors. Ecology: achievement and challenge. Blackwell Science, Oxford, UK.

Michmerhuizen, C. M., R. G. Striegl, and M. E. McDonald. 1996. Potential methane emission from north-temperate lakes following ice melt. Limnology and Oceanography 41:985991.

National Ecological Observatory Network (NEON). 2010. Field site and sampling strategy. http://www.neoninc.org/ science/domains\#sitelist

Newbrey, J. L., M. A. Bozek, and N. D. Niemuth. 2005. Effects of lake characteristics and human disturbance on the presence of piscivorous birds in Northern Wisconsin, USA. Waterbirds 28:478-486.

Nõges, T. 2009. Relationships between morphometry, geographic location and water quality parameters of European lakes. Hydrobiologia 633:33-43.

Novotny, E. V., D. Murphy, and H. G. Stefan. 2008. Increase of urban lake salinity by road deicing salt. Science of the Total Environment 406:131-144.

Oertli, B., D. A. Joye, E. Castella, R. Juge, D. Cambin, and J. Lachavanne. 2002. Does size matter? The relationship between pond area and biodiversity. Biological Conservation 104:59-70.

Parkman, A. 1983. History of the waterways of the Atlantic Coast of the United States. National Waterways Study. U.S. Army Engineer Water Resources Support Center, Institute for Water Resources, Alexandria, Virginia, USA.

Paul, M. J., and J. L. Meyer. 2001. Streams in the urban landscape. Annual Review of Ecological Systems 32:333-365.

Roach, W. J., J. B. Heffernan, N. B. Grimm, J. R. Arrowsmith, C. Eisinger, and T. Rychener. 2008. Unintended consequences of urbanization for aquatic ecosystems: a case study from the Arizona desert. BioScience 58:715-727.

Roy, A. H., A. L. Dybas, K. M. Fritz, and H. R. Lubbers. 2009. Urbanization affects the extent and hydrologic permanence of headwater streams in a midwestern U.S. metropolitan area. Journal of the North American Benthological Society 28:911-928.

Schagerl, M., I. Bloch, D. G. Angeler, and C. Fesl. 2010. The use of urban clay-pit ponds for human recreation: assessment of impacts on water quality and phytoplankton assemblages. Environmental Monitoring and Assessment 165:283-293.

Schneider, A., M. A. Friedl, and D. Potere. 2009. A new map of global urban extent from MODIS satellite data. Environmental Research Letters 4:044003.

Seekell, D. A., and M. L. Pace. 2011. Does the Pareto distribution adequately describe the size-distribution of lakes? Limnology and Oceanography 56:350-356.

Seekell, D. A., M. L. Pace, L. J. Tranvik, and C. Verpoorter. 2013. A fractal-based approach to lake size distributions. Geophysical Research Letters 40:517-521.

Shurin, J. B., K. Cottenie, and H. Hillebrand. 2009. Spatial autocorrelation and dispersal limitation in freshwater organisms. Oecologia 159:151-159.

Somers, K. A., E. S. Bernhardt, J. B. Grace, B. A. Hassett, E. B. Sudduth, S. Wang, and D. L. Urban. 2013. Streams in the urban heat island: spatial and temporal variability in temperature. Freshwater Science 32:309-326.
Søndergaard, M., E. Jeppesen, and J. P. Jensen. 2005. Pond or lake: does it make any difference? Archiv für Hydrobiologie $162: 143-165$

Stallard, R. F. 1998. Terrestrial sedimentation and the carbon cycle: coupling weathering and erosion to carbon burial. Global Biogeochemical Cycles 12:231-257.

Stander, E. K., and J. G. Ehrenfeld. 2009. Rapid assessment of urban wetlands: do hydrogeomorphic classification and reference criteria work? Environmental Management 43:725-742.

Steele, M. K., et al. 2014. Convergent surface water distributions in U.S. cities. Ecosystems, in press.

Steele, M. K., W. H. McDowell, and J. A. AitkenheadPeterson. 2010. Chemistry of urban, suburban, and rural surface waters. Pages 297-339 in J. A. Aitkenhead-Peterson and A. Volder, editors. Urban ecosystem ecology. Agronomy Monograph 55. Agronomy Society of America, Madison, Wisconsin, USA.

Stomp, M., J. Huismand, G. Mittelbach, E. Litchman, and C. Klausmeier. 2011. Large-scale biodiversity patterns in freshwater phytoplankton. Ecology 92:2096-2107.

Sun, R., A. Chen, L. Chen, and Y. Lü. 2012. Cooling effects of wetlands in an urban region: the case of Beijing. Ecological Indicators 20:57-64.

Sun, R., and L. Chen. 2012. How can urban water bodies be designed for climate adaptation? Landscape and Urban Planning 105:27-33.

Trimble, S. W. 2003. Historical hydrographic and hydrologic changes in the San Diego creek watershed, Newport Bay, California. Journal of Historical Geography 29:422-444.

United Nations. 2011. Population distribution, urbanization, internal migration, and development: and international perspective. United Nations Publication. UN Department of Economic and Social Affairs, New York, New York, USA.

USGS (United States Geologic Survey). 2012. National Hydrography Dataset, by state, high resolution. USGS, Washington, D.C., USA.

Van Metre, P. C. 2012. Increased atmospheric deposition of mercury in reference lakes near major urban areas. Environmental Pollution 162:209-215.

Van Metre, P. C., and B. J. Mahler. 2010. Contribution of PAHs from coal-tar pavement sealcoat and other sources to 40 U.S. lakes. Science of the Total Environment 409:334344.

Walsh, C. J., A. H. Roy, J. W. Faminella, P. D. Cottingham, P. M. Groffman, and R. P. Morgan. 2005. The urban stream syndrome: current knowledge and the search for a cure. Journal of the North American Benthological Society 24:706-723.

Williams, C. J., P. C. Frost, and M. A. Xenopoulos. 2013. Beyond best management practices: dynamics in urban stormwater ponds. Ecological Applications 23:1384-1395.

Williams, P. 2004. Comparative biodiversity of rivers, streams, ditches and ponds in an agricultural landscape in Southern England. Biological Conservation 115:329-341.

Woolnough, D. A., J. A. Downing, and T. J. Newton. 2009. Fish movement and habitat use depends on water body size and shape. Ecology of Freshwater Fish 18:83-91. 